\title{
A MELHORIA DO ENSINO DOS CONTEÚDOS GEOLÓGICOS DAS SÉRIES INICIAIS AO ENSINO MÉDIO
}

\author{
Juliana Chioca Lopes \\ Bolsista de Iniciação Científica do Dep. de Geografia - UFU \\ Adriano Rodrigues dos Santos \\ Prof. Do Dep. de Geografia - UFU
}

RESUMO: Neste trabalho, tendo como público alvo professores e alunos da rede escolar pública e particular de Uberlândia, procurou-se abordar temas relacionados às Geociências, que, normalmente, não são enfatizados no ensino fundamental e médio, quer por deficiência curricular, quer por despreparo dos docentes responsáveis. O principal objetivo é oferecer apoio e acompanhamento à atividades, fornecimento de recursos e infra estrutura básica. Apesar do esforço empreendido em três anos de trabalho em conjunto com aproximadamente 50 escolas, nota-se diferentes níveis de envolvimentos das mesmas. Conclui-se, portanto, que um trabalho de tal magnitude deverá ser encarado com atividade extensionista permanente envolvendo profissionais ligados à área educacional, a museus, entre outros, tanto de nível fundamental e médio como das Universidades.

Palavras chaves: geociências, museu, educação.

\section{INTRODUÇÃO}

Os tópicos constituintes das chamadas Geociências, tais como Geologia, Mineralogia, Pedologia e Paleontologia possuem estreita relação com o cotidiano das pessoas, pois condizem aos aspectos da natureza e do trabalho, assim como das relações calcadas sobre o meio, contribuindo, ainda, para a compreensão crítica do mesmo.

Paradoxalmente à importância de tais conteúdos no desenvolvimento social, mais que escolar, presencia-se nos níveis fundamental e médio de ensino da cidade de Uberlândia um quadro desfavorável tanto ao processo de aprendizagem quanto à ação pedagógica dos educadores em se tratando de Geociências. Essa situação se faz presente a nível nacional, não havendo, dessa formas, grandes modificações na rede de ensino do Estado de Minas Gerais, e, em especial, da cidade de Uberlândia: quase completa exclusão dos assuntos geológicos por parte dos Programas Oficiais de Ensino, inexistência de disciplina específica destinada aos tópicos de Geologia, e ainda, carência de infra estrutura escolar adequada, entre outros.

Levando-se em consideração que as pessoas, inclusos aí professores e alunos, relacionam-se com o meio, produzem o espaço e exploram seus recursos de forma que se torna impossível a dissociação entre eles e da preocupação com a importância dos conhecimentos geológicos e ao mesmo tempo da pouca relevância dada a eles nos níveis de ensino é que surgiu o trabalho. $O$ objetivo maior consiste em trabalhar junto aos professores e alunos, informando e oferecendo recursos no sentido de tornar acessível e eficaz o ensino dos assuntos geológicos. Para tanto, dando suporte ao desenvolvimento de atividade está a infra estrutura do Museu de Minerais e Rochas da UFU, assim como dos Laboratórios do Departamento de Geografia. A partir dessas ações tem sido possível diagnosticar as reais carências do ensino das Geociências. 
Dessa forma, há aproximadamente 3 anos tem-se realizado trabalhos integrados com a comunidade escolar realizados nas próprias instituições de ensino, incluindo discussões, produção de materiais pedagógicos, orientação à pesquisa científica escolar, promoção de cursos e palestras, planejamento e realização de atividades em campo, classificação de acervos didáticos entre outros. Ainda temse buscado a dinamização do Museu de Minerais e Rochas da Universidade Federal de Uberlândia, atribuindo-Ihe caráter pedagógico. Tem-se, ainda, priorizado a realização de atividades em campo junto às escolas envolvidas no sentido de unir teoria e prática em benefício do ensino e da aprendizagem.

Dessa forma, os objetivos propostos e as atividades desenvolvidas convergem em uma meta maior, que é a de interferir na prática cotidiana dos profissionais do ensino e também na construção de conhecimentos por parte do aluno, sendo que, intermediando estes processos estejam a criatividade, a crítica e, principalmente o descobrir o prazer em estudar as Geociências.

\begin{abstract}
"Estimular o prazer em praticar e estudar as ciências básicas naturais, observar e interagir com a natureza e fomentar a criatividade pode ser implementado utilizando as Geociências como vetor no processo educativo" (BARCELOS, 1993 : 121)
\end{abstract}

\section{TRABALHO INTEGRADO À COMUNIDADE ESCOLAR}

O contato com os objetos de estudo das Geociências ocorre no cotidiano das pessoas, no estabelecimento de relações entre sociedade e natureza. Contudo, a escola tem sido, ao longo dos tempos, estabelecida como o local específico de produção e transmissão de conhecimentos. Assim, buscando integração com a comunidade escolar, a exposição dos objetivos e justificativas, realizada inicialmente junto aos diretores das escolas por intermédio de telefonemas e correspondências, passou a ser realizada por meio do contato direto, no qual, predominantemente, a iniciativa partia do próprio professor, já ciente das propostas do trabalho. Dessa forma, as escolas, aproximadamente em número de 50 , tem contado com apoio e orientação a seus professores e alunos.

De acordo com as necessidades e carências enfrentadas individualmente por educadores em sua prática cotidiana, nos próprios estabelecimentos de ensino desenvolveram-se atividades como planejamento e discussão de atividades, classificação de acervo escolar e doação de amostras, orientação de trabalhos de amostras científicas ou eventos semelhantes, desenvolvimento de experiências e trabalhos práticos, cursos e palestras. Foto 1.

Tais atividades buscaram,

“... propiciar ao aluno o aprendizado através da vivência dos processos pelos quais se obtém o saber científico, construindo a compreensão dos fatos, conceitos, princípios, leis, teorias científicas ... com a ciência passando a ser considerada uma atividade humana teórico prática em constante construção ..."(COMPIANI, 1988:05).

O trabalho realizado nas escolas integradas constituem apenas uma fase do trabalho, pois também tem-se desenvolvido ações no Museu de Minerais e Rochas e saídas a campo, contudo estas não são etapas sucessivas.

A interação às propostas da pesquisa pode ocorrer por meio de palestra na escola, visita ao museu e atividade em campo, ou por meio de atividades somente em um dos 


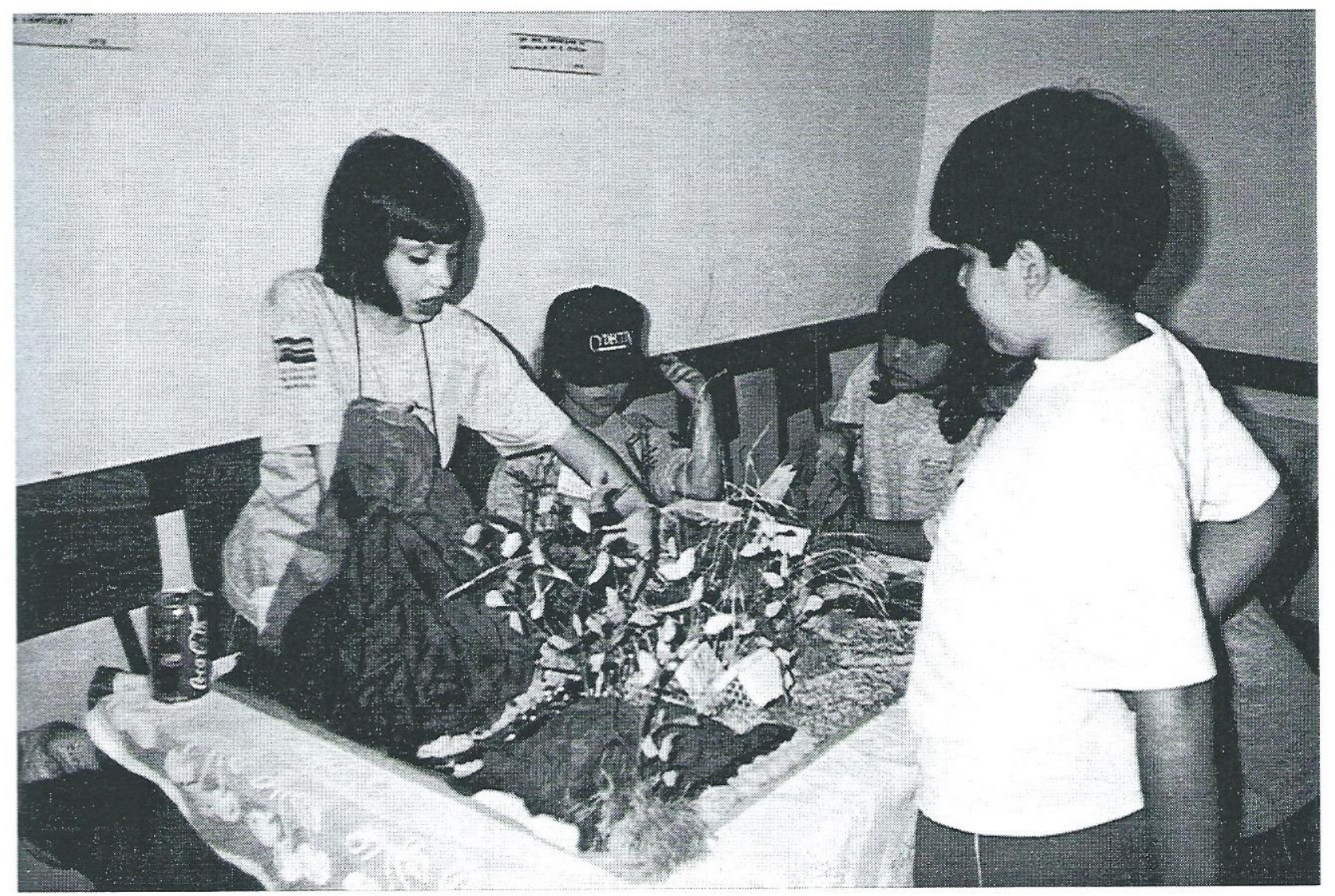

Foto 1. Trabalho orientado de amostra científica. Alunos da $3^{\text {a }}$ série do ensino fundamental. Centro Educacional Mondragon.

Foto dos autores / 1995.

espaços citados, por meio de atividades continuadas em alguns casos e estanques, infelizmente, em outros.

O fato é que existe grande diferenciação no nível de envolvimento com professores e alunos da rede escolar.

Assim, mais que apoiar professores na melhoria de suas aulas oferecendo recursos alternativos e criando situações novas que possibilitem o despertar do interesse dos alunos para os assuntos em questão, tem-se buscado conhecer a realidade escolar, propor e discutir a possibilidade de várias ações dentro da temática do ensino, favorecendo a crescente capacidade de inovar, e de buscar os mecanismos da interdisciplinaridade e das relações práticas estabelecidas na realidade para 0 favorecimento do ensinar e do aprender.

Além disso a atuação junto aos educadores atenta para a importância da reflexão sobre a prática pedagógica cotidiana e seus reflexos na formação de alunos cidadãos.

Contudo, é válido ressaltar que não existe a intensão de serem ditadas as ações dos educadores.

O trabalho volta-se para o acompanhamento, planejamento e essencialmente discussões depois colocadas em prática. 
"Cada professor precisa saber propor seu modo próprio e criativo de teorizar e praticar a pesquisa, renovando-a constantemente e mantendo-a como fonte principal de sua capacidade inventiva"(DEMO, 1996)

\section{O MUSEU DE MINERAIS E ROCHAS}

O Museu de Minerais e Rochas da UFU foi criado em 1987 e está ligado ao Departamento de Geografia da Universidade Federal de Uberlândia.

Conta com uma ampla sala de exposição com vitrines que expõem mais de 500 espécies de amostras minerais de diversas regiões do país, principalmente do Estado de Minas Gerais. (Foto 2).

O espaço ainda conta com laboratório onde são ministradas aulas teóricas e práticas de Geologia para alunos de diversos cursos de graduação.

No Museu encontra-se uma sala de preparação de amostras, um anfiteatro para palestras e exposições de filmes, além de reserva técnica.

Tendo em vista essa infra-estrutura, o trabalho tem trazido as escolas da rede oficial e particular da cidade e entorno para realização de atividades que colaborem para a melhoria do ensino dos conteúdos geológicos.

Durante os 3 anos de existência da interação entre comunidade escolar e Universidade, o Museu de Minerais e Rochas tem atendido à sua função pedagógica, propiciando o desenvolvimento de atividades práticas, experiências, pesquisa, entre outros.

Busca-se, junto às várias turmas que visitam o Museu realizar um trabalho de definição de objetivos e planejamento da atividade, para que seja possível extrapolar o aspecto unicamente visual e extremamente científico mostrado na exposição.

Para que a construção de conhecimentos norteada pela crítica, prazer e criatividade seja alcançada considera-se fundamental possibilitar a experiência, o contato do visitante com o objeto de estudo por meio da pesquisa e da prática. (Foto 2)

Contudo, vale ressaltar que,

“... cabe aos museus, no âmbito da educação e da formação cultural, um papel diferenciado da escola. Os museus, enquanto instituições de comunicação e de difusão cultural, com funções específicas ... atuam em campos educacionais outros, que não o da educação seriada, regular, sistemática”. (LOPES, 1988:156)

A exposição do museu desperta a atenção do público em função da beleza e raridade das amostras, porém, o significado da existência de Instituições museológicas não é apenas expor objetos bonitos e exóticos, acredita-se que eles tais objetos devem ser capaz de levantar questionamentos, de despertar o visitante para a sua função social real.

Para tanto acredita-se ser fundamental a mudança da dinâmica do Museu de Minerais e Rochas, obtida, paulatinamente, por meio das atividades junto às escolas de nível fundamental e médio.

"A divulgação científica contribuiria para incentivar a vivência, a familiariedade com o método científico, não de maneira a absolutizá-lo como a única visão possível de mundo, mas pelo contrário, de modo a compreendê-lo como mais uma leitura do mundo e questioná-lo". (LOPES, 1988: 157) 


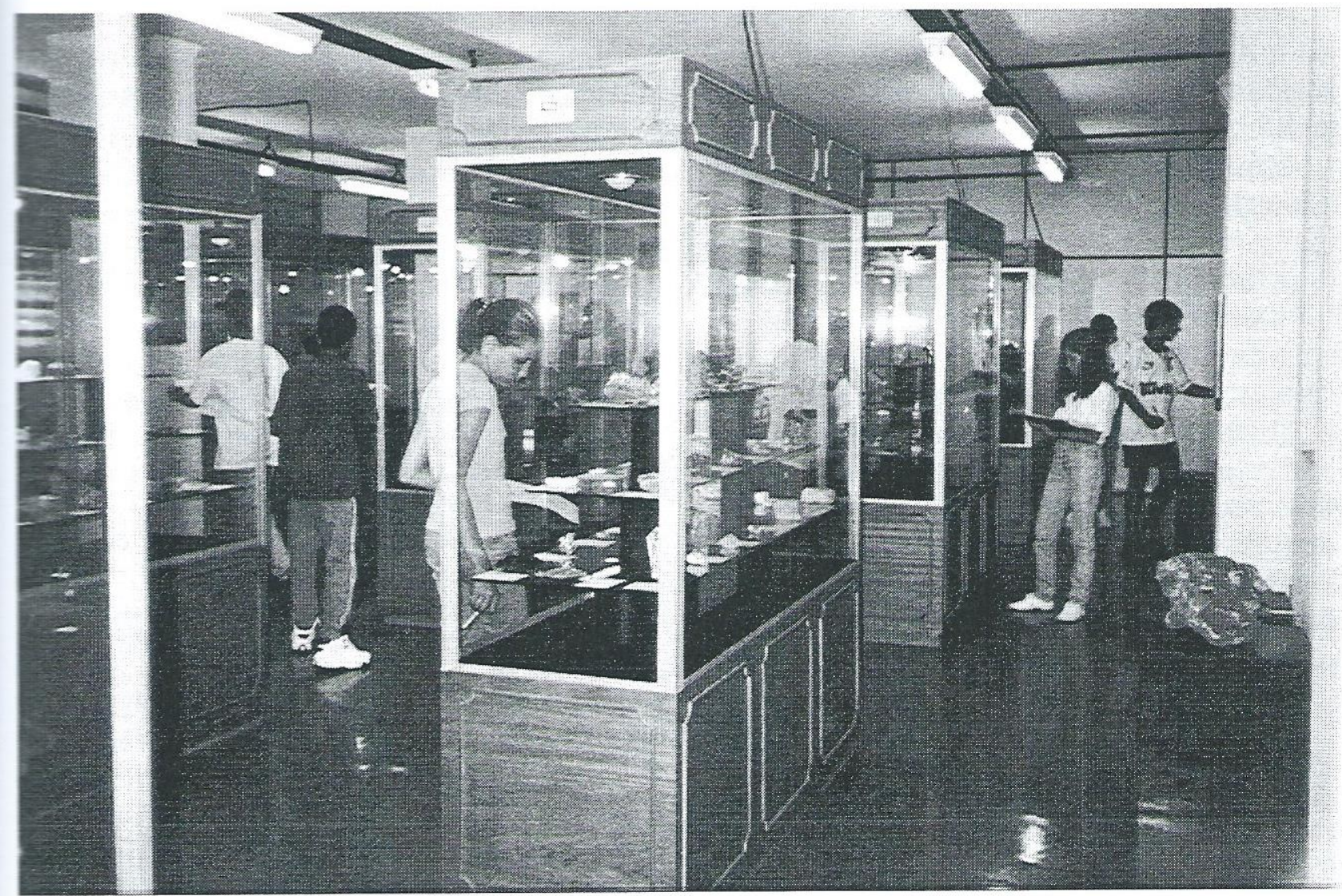

Foto 2: Visita e atividades orientadas ao Museu de Minerais e Rochas da UFU. Alunos da $5^{\text {a }}$ série. Escola Estadual "Messias Pedreiro".

Foto dos Autores / 1996

\section{Atividades em Campo}

O hábito da realização de atividades extra classe não é comum na maioria das escolas de ensino fundamental e médio. Imperam como recursos educacionais as aulas expositivas, o cumprimento de programas e livros didáticos e as avaliações punitivas.

Contudo, em especial em Geociências, o conhecer e tocar os objetos de estudo é fundamental para a aprendizagem, e o trabalhar as atividades em campo não é tão complicado e inviável.

As atividades fora de classe no campo das Geociências podem ser realizadas nos arredores da própria escola ou no Bairro, em um praça ou parque, e ainda em qualquer local onde seja possível interagir com a natureza e constatar as ações humanas sobre o meio.

Dessa forma, tem-se trabalhado em conjunto com professores de Geografia e Ciências, além de profissionais de outros áreas de interfácie com as Geociências, no sentido orientar a realização de trabalhos em campo com alunos dos mais variados níveis escolares.

O trabalho integrado vem atendendo à sugestão e elaboração de roteiros, preparação da turma, levantamento de materiais necessários ao campo e atividade em si. 
Até o momento poucas são as escolas envolvidas em atividades de campo em função do caráter quase inédito do trabalho, contudo, já foram realizadas atividades dentro da área urbana.

Podem ser citados os locais onde são sérios os problemas de erosão do solo e de degradação ambiental e exploração de recursos; as áreas um pouco mais distantes da cidade, como em antiga estrada ligando Uberlândia à Araguari, para o conhecimento dos aspectos fisiográficos locais; a região de Araxá com visita às empresas mineradoras presentes; e ainda, o distrito de Peirópolis Uberaba, com seu sítio paleontológico expressivo. (Foto 3).
O trabalho de incentivo às escolas para que realizem as saídas a campo, assim como o fornecimento de bases para tal ação, como planejamento, discussão, execução e avaliação de resultados, justifica-se pela certeza de que as atividades extra classe favorecem o aprendizado coeso em Ciências Geológicas, pois levam

“... o aluno a refletir sobre a complexidade e integração dos fenômenos naturais ... e também criar uma postura no educando com relação aos problemas atuais do desequilíbrio ecológico, sensibilizando-o para a compreensão do papel desempenhado pelo homem na sua interferência na natureza". (DEL GROSSI, 1992:123).

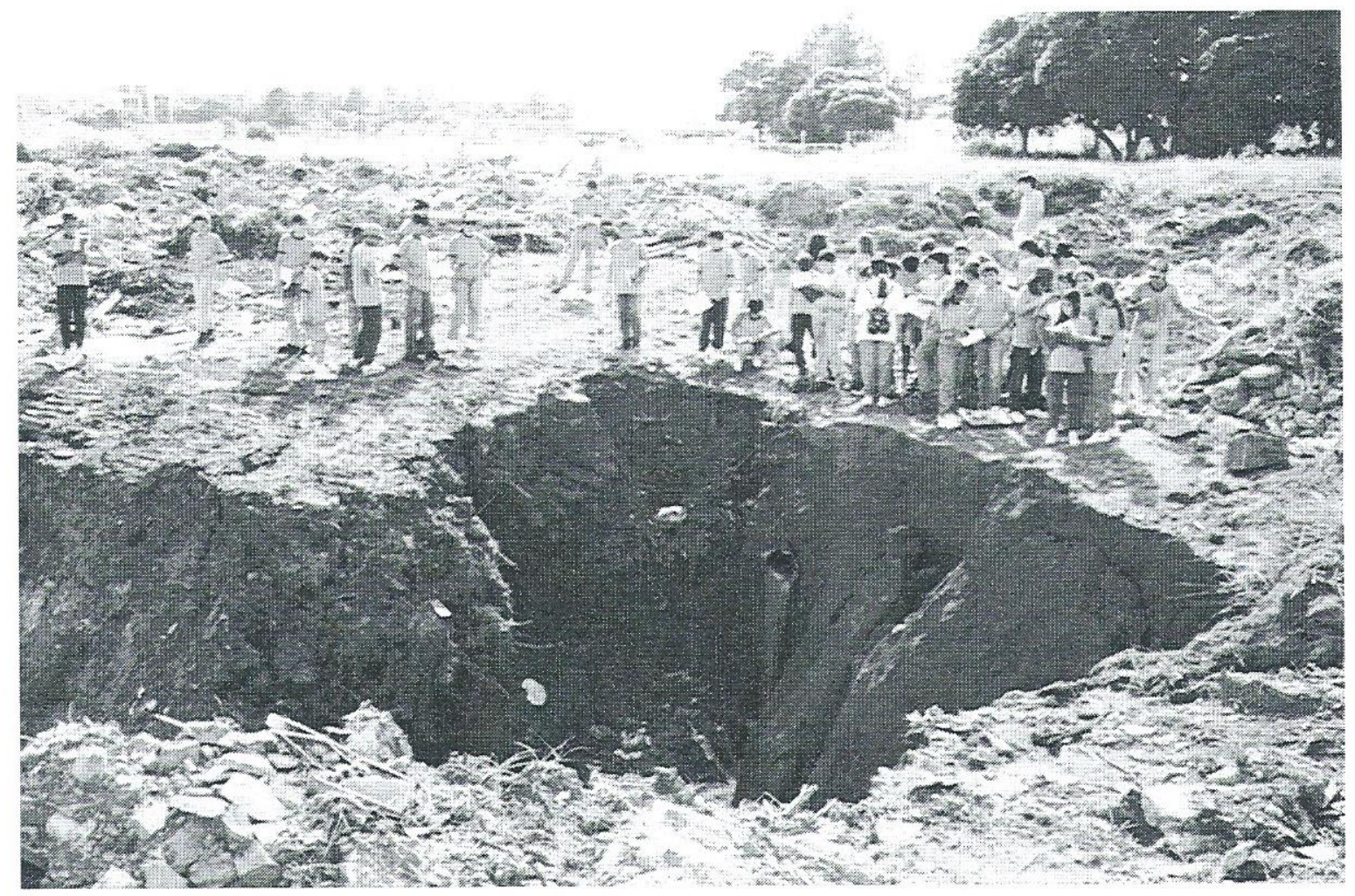

Foto 3: Atividade orientada em campo - erosão do solo e degradação ambiental no Bairro Marta Helena.

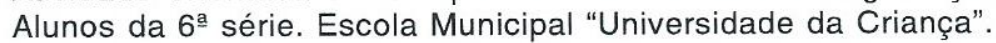

Foto dos autores / 1995 
Busca-se, por fim, direcionar o trabalho de maneira em que o aluno mostrese ativo, interpretando, descrevendo, coletando material, discutindo.

Para tanto, é necessário que se trabalhe com as pessoas envolvidas (professores e alunos) no sentido de descobrir a dinâmica da natureza, as ações que a modificam contextualizadas historicamente. Isso se resume, em concordância com (COMPIANI, 1988), em inferir ao trabalho de campo o enfoque educacional formativo.

\section{DISCUSSÕES}

A função primordial da pesquisa científica, realizada por quaisquer áreas do conhecimento, é a de solucionar problemas e deferir aplicabilidade social a seus resultados. Os frutos dos trabalhos acadêmicos deixam de possuir mérito real na medida em que não possuem valor ou sentido para a sociedade que os sustentam.

Tais preocupações têm motivado o andamento do trabalho desenvolvido junto à rede escolar de ensino fundamental e médio de Uberlândia. Todos os semestres o Museu de Minerais e Rochas ganha vida com as visitas e trabalhos realizados por diversos estabelecimentos de ensino, que também buscam a melhoria do ensino e da aprendizagem em Ciência Geológica a partir de várias outras formas, como as atividades em campo, as Feiras Científicas, as palestras e trabalhos práticos.

Contudo, algumas escolas apresentam maiores preocupações e amadurecimento frente aos objetivos propostos que outros. À título de exemplificação pode-se citar a Escola Municipal "Universidade da Criança", o Centro Educacional Mondragon, a Escola Estadual Messias Pedreiro, a "Escola da Criança, e algumas outras. Nestas instituições o envolvimento com as atividades, e principalmente, a noção da importância dos conteúdos das Ciências da Terra assim como da necessidade do desenvolvimento de metodologias adequadas para o seu ensino tem substituído o acompanhamento e o apoio inicial pela parceria.

Esse progresso é essencial visto o caráter finito do trabalho, contudo se deixarem de existir os recursos e infra estrutura oferecidos pela Universidade, mesmo assim os conteúdos geológicos continuarão sendo bem trabalhados em sala de aula se os educadores, além da noção de sua importância, tiverem amadurecidas as melhores formas de trabalhá-los.

\section{REFERÊNCIAS BIBLIOGRÁFICAS}

COMPIANI, M. O Fazer Geologia com Ênfase no Campo na Formação de Professores de Ciências para o 1 Grau (5 a $8^{\text {a }}$ séries). Campinas: Faculdade de Educação da UNICAMP, 1988. (Dissertação, Mestrado).

LOPES, M. M. O Outro Lado da Especialização: uma esperiência de divulgação do conhecimento geológico em museu. In: Simpósio Especialização em Ensino de Geociências no $3^{\circ}$ Grau, 1, Campinas, 1988. Anais. Campinas: UNICAMP, p. 155-163. 1988.

DEL GROSSI, S. R. Trabalho de Campo em Geociências: sugestão de um modelo de roteiro. Sociedade \& Natureza. Uberlândia: EDUFU, no 7/8, p.123-125, jan/dez, 1992.

BARCELOS, J. H. As Geociências como Vetor no Processo Educativo. Sociedade \& Natureza. Uberlândia: EDUFU, nำ 9/10, p. 121-124, jan/dez. 1993.

DEMO, P. Educar pela Pesquisa. Campinas: Autores Associados, 1996. 